\title{
Movement Therapy of the Upper Extremities with a Robotic Ball in Stroke Patients: Results of a Randomized Controlled Crossover Study
}

\section{(ㄷ) (1) (우) $\odot$}

\author{
Authors \\ Tilo Neuendorf, Daniel Zschäbitz, Nico Nitzsche, Henry Schulz
}

\author{
Affiliation \\ Technische Universität Chemnitz - Sportmedizin/-biologie, \\ TU Chemnitz - Institut für Angewandte \\ Bewegungswissenschaften, Chemnitz \\ Key words \\ stroke, motor function, robotic ball, upper extremities, \\ exergaming \\ Bibliography \\ DOI https://doi.org/10.1055/s-0043-122200 \\ Neurology International Open 2017; 1: E326-E335 \\ (c) Georg Thieme Verlag KG Stuttgart · New York \\ ISSN 0000-000X \\ Correspondence \\ Tilo Neuendorf \\ Technische Universität Chemnitz - Sportmedizin/-biologie \\ TU Chemnitz - Institut für Angewandte \\ Bewegungswissenschaften \\ Thüringer Weg 11 \\ 09126 Chemnitz \\ Germany \\ tilo.neuendorf@hsw.tu-chemnitz.de
}

\section{ABSTRACT}

Background Stroke is associated with motor impairments of the upper extremities. The defining goal of rehabilitation is independent execution of activities of daily living. New therapy procedures use different hardware components to implement digital therapy contents. These can be useful complements to established therapy protocols.

Objectives The aim of this study was to examine the effect of movement therapy with a robotic ball on motor function parameters in stroke patients.

Materials and Methods 25 patients $(60.0 \pm 10.0$ years, $172.5 \pm 13.8 \mathrm{~cm}, 79.5 \pm 13.8 \mathrm{~kg}, 89.8 \pm 72.6$ months poststroke) took part in this crossover study. The intervention and control periods comprised 12 weeks each. Training with the robotic ball was done in addition to standard therapy two times a week for 45 min each. Different game activities were carried out with the help of a tablet and a smartphone.

Results Isometric grip strength improved by $4.5 \pm 3.6 \mathrm{~kg}$ $(p=0.000)$, and unilateral dexterity increased by $7.5 \pm 6.3$ successful tries $(p=0.000)$ in the round block test. The self-reported disabilities of the arm, shoulder and hand were assessed using the QuickDASH questionnaire and showed improvements by $12.4 \pm 13.0$ points $(p=0.001)$.

Conclusions Additional therapy using the robotic ball improved upper extremity motor function and self-perceived health status in chronic stroke patients. However, performance stagnated when standard therapy was implemented alone. Moderately affected patients seem to benefit the most. The presence of very severe motor or cognitive symptoms led, in part, to some dropouts. The results need to be verified using larger patient populations.

\section{Introduction}

In Germany, up to $75 \%$ of the approx. 196,000 initial and 66,000 repeated strokes are survived [1-4]. For the affected patients, it is often the trigger for persistent physical limitations, which in $85 \%$ of the cases are manifested by the cardinal symptom of spastic or flaccid hemiparesis of the upper extremities. Restriction or even loss of function of the hand and arm drastically impacts the daily life of the affected individual [1,5-7]. Demographic change has in- creased the incidence of stroke. Improved acute care has enabled more people to survive the event, resulting in a greater number of patients and a growing demand for therapy $[1,2,6]$. Reduced range of motion, pain, sensory disturbances and increased muscle tone are characteristic patient symptoms $[8,9]$. Loss of arm function is the consequence in about half of stroke cases [8], unlike rehabilitation of independent mobility, which can be achieved in up to $85 \%$ of patients [10]. Consequently, relatively less time is devoted to re- 
covery of hand and arm function [11]. In addition to effects on motor function there are often psychological and social consequences [12]. A variety of physical activity measures should contribute to the compensation and restoration of skills and abilities $[13,14]$. Since it is still possible to make progress even weeks after a stroke, it is imperative to develop more effective therapeutic methods, especially in the case of sustained loss of upper extremity function [8]. Thus the severity and location of the cerebral insult as well as comorbidities are decisive for the further rehabilitation process $[15,16]$. The success of Constraint-induced Movement Therapy (CIMT) [7, 17-24] demonstrates the necessity and possible benefit of using the upper extremities during training and everyday life.

In this context as well as due to innovative developments in technology-supported concepts and components [25-30] in the field of stroke rehabilitation such as exergaming, [31-34] the "Sphero 2.0 " robotic ball was reviewed in combination with game-playing applications as a supplemental therapeutic activity [35]. The potential benefit for stroke patients regarding improving motor parameters has been documented in review articles on technology-supported therapeutic measures [36, 37]. Hardware and software components from the entertainment industry or telecommunications are used to develop new therapy activities. There are examples of the Microsoft Kinect webcam used in stroke

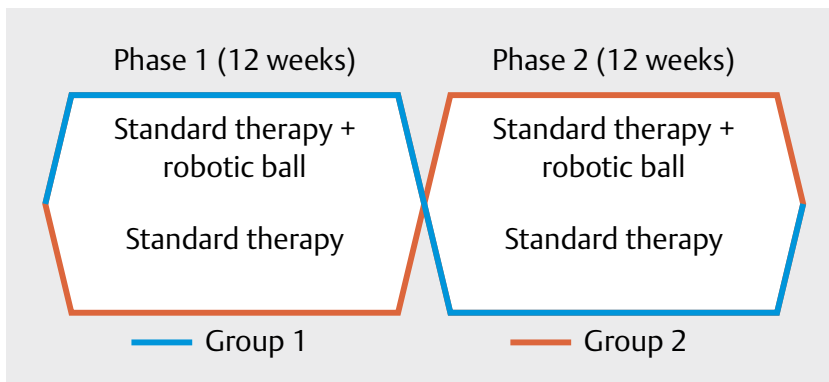

- Fig. 1 Study design and phases.

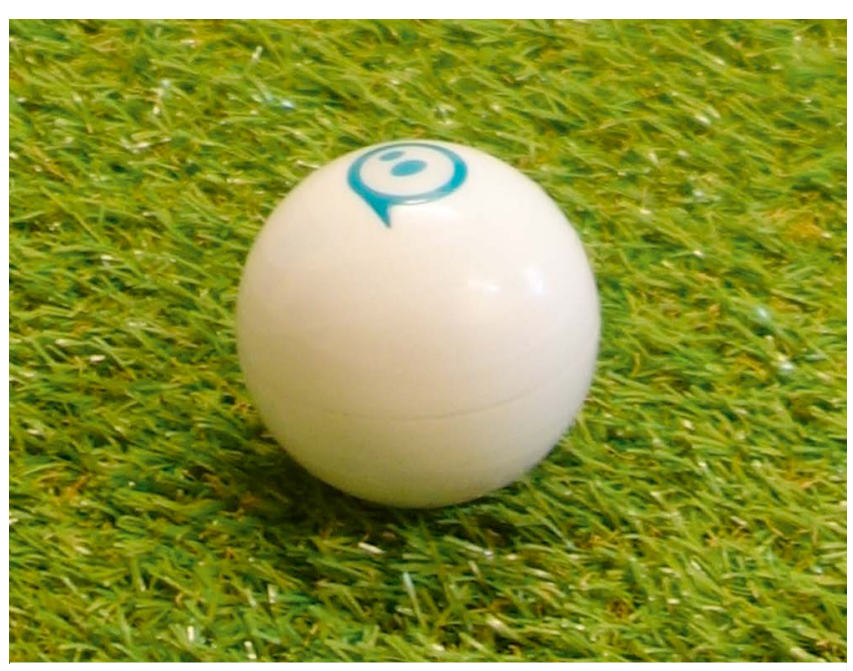

- Fig. 2 The "Sphero 2.0" robotic ball by Orbotix (Boulder, CO, USA). rehabilitation [30, 38-44] as well as for game consoles such as the Nintendo Wii [45-47], Sony Playstation [48] or Microsoft XBox [44]. In addition, smartphones [34], tablets [49-52] or virtual reality goggles [53] are being used to employ generally commercially available games with potential therapeutic benefits, or to use their sensor systems for movement detection and control. Therapeutic content can be found in commercial video games such as Wii Sports [54] or Kinect Sports [44] as well as games programmed specifically for therapeutic applications $[42,55]$. Their common element is the required use of the affected body half to achieve the respective game objective. The activity can reflect daily activities such as grasping and moving a glass [56], cooking [38], or striking selected piano keys $[38,49]$.

\section{Objective and Issues Addressed}

The effect of movement therapy of stroke patients utilizing a robotic ball based on selected motor parameters will be investigated using a crossover study design. The motor functionality of the upper extremities will be quantified using subjective and objective assessments. The aim is to investigate the effect of a robotic ball with various play activities in addition to standard therapy.

\section{Methodology}

\section{Study design}

The study was conducted based on a crossover design. Group 1 started in Phase 1 with standard therapy, supplemented by robotic ball therapy; Phase 2 used only standard therapeutic procedures. The process for Group 2 was reversed ( $\triangleright$ Fig. 1). Training with the robotic ball involved 24 units for each patient, two times per week, each $45 \mathrm{~min}$ in duration. Standard therapy (generally 1-2 applications during 1-2 sessions per week) included physiotherapy and occupational therapy, and as needed, logotherapeutic activities. These included classical physiotherapeutic approaches such as remedial gymnastics for neurological diseases (Bobath, Vojta and PNF) as well as neuromuscular electrostimulation. Furthermore, mobilizing therapy exercises with heat application (fango, ultrasound, hot roller), classical massages or manual therapy were used; edema was treated with lymph drainage. Occupational therapy included motor-functional, sensomotor-perceptive, psychological as well as neuropsychological treatment measures. The study was reviewed and approved by the local ethics committee (VS-129-HS).

\section{Sampling}

After prior verbal and written disclosure, 25 stroke patients volunteered for the study which was conducted in an outpatient rehabilitation center, respecting patient privacy ( $\triangleright$ Table 1 ). Twenty-three of the patients had experienced a stroke more than 6 months prior to the study [57].

\section{Hardware/software}

Supplemental training employed the "Sphere 2.0" robotic ball (Orbotix, Colorado, USA) using firmware ver. 3.73 ( $\triangleright$ Fig. 2). The applications were controlled using a Cubot X15 smartphone (Android 

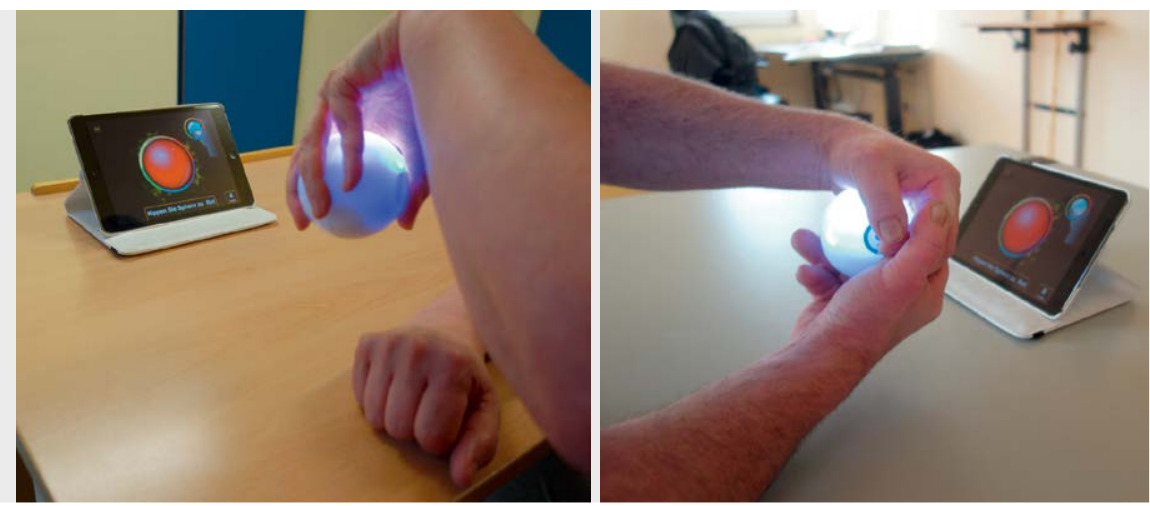

Fig. 3 The "Chromo" game in both variants: unilateral and bilateral.
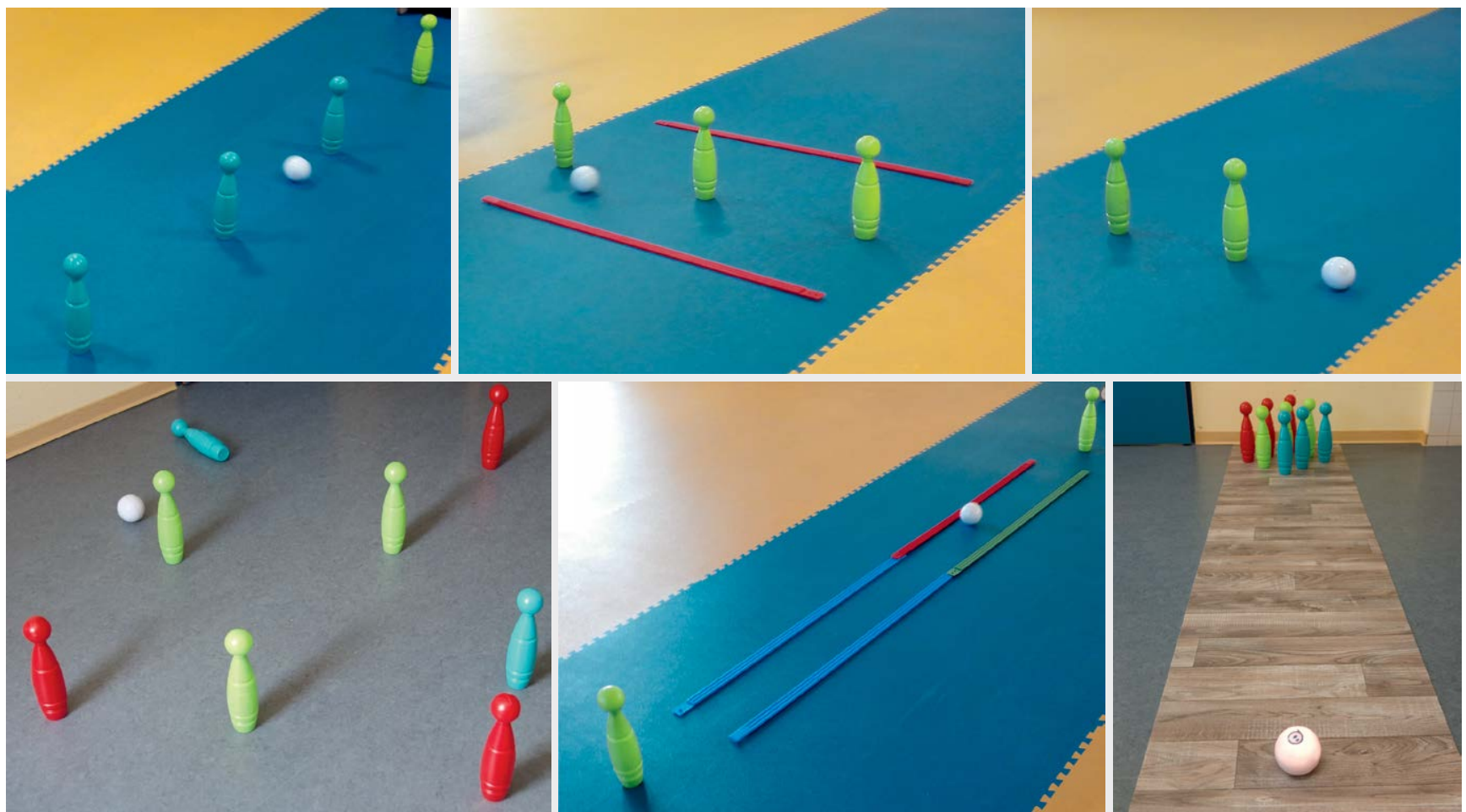

- Fig. 4 "Sphero" game structure variations.

5.1) as well as an Apple Mini 2 iPad (iOS 9.2-10.2). In addition, a specially-developed holder was used as an aid is grasping the smartphone [35]. The therapeutic actions were implemented using the "Sphero" and "Sphero Chromo" apps.

\section{Therapeutic activities}

By moving the upper extremities, especially the hand, the patient actively tries to achieve the objectives of the respective game. The robotic ball is either held in the hand and turned in various directions (Chromo app) ( $\triangleright$ Fig. 3) or remotely controlled by moving the smartphone (Sphero app) (\ Fig. 4). The study director performs device setup, configures motion tasks and provides support during patient training.

In addition to the wrist, the patient also partially moves the elbow and shoulder joints to involve the complete hand-arm-shoul- der chain. Another challenge is the ability to grasp and turn the ball in a variety of ways. Numerous exercise variations allow a wide range of therapeutic options depending on symptom manifestation. Simple aids (tenpins, floor mats, bars) can also be used to create new movement tasks ( $>$ Fig. 4).

\section{Test procedures}

Patient cognitive status was determined using the Montreal Cognitive Assessment. A result greater than 26 points is considered "normal" [58]. Motor function was determined using isometric grip strength for 1-2 s (starting with the affected side, 3 attempts; healthy side as reference in 2 attempts). This parameter is used as a marker for global functionality of the upper extremities as well as a measurement of rehabilitation progress $[59,60]$. The round block test was selected to determine unilateral dexterity of gross motor 
movements. Within $60 \mathrm{~s}$, as many cylinders as possible (diameter $6.5 \mathrm{~cm}$, thickness $2 \mathrm{~cm}$ ) are turned with one hand into recesses $(0.5 \mathrm{~cm})$ on a wooden board (starting with the affected side, 3 attempts; healthy side as reference in 2 attempts). In addition, the QuickDASH questionnaire assessed the subjective perception of the affected person with regard to their current state of health $(0$ points $\cong$, no impairment up to 100 points $\triangleq$, maximum possible restriction) of the upper extremities [61, 62]. A difference of at least 14 points is considered clinically relevant [63].

In order to carry out a differentiated data analysis, three performance classes were formed for the parameters grip strength, unilateral dexterity and personal health perception. Grouping patients as "severely affected", "moderately affected" and "mildly affected" should help to specify the suitability of the therapy concept and to make apparent any differences depending on the degree of impairment. Classification was done after randomization in percentage relation to the healthy half of the body (grip strength, round block) or to the lowest score as a measure of no impairment (QuickDASH). Severely affected $\triangleq \leq 20 \%$, moderately affected $\triangleq 20$ to $\leq 75 \%$ and mildly affected $\triangleq>75 \%$.

\section{Statistics}

Statistical analysis was performed using IBM SPSS Statistics version 24 . The significance level was defined as $\alpha=5 \%$. The pre/post comparison of the results used the nonparametric Wilcoxon test measurement method and sign test. The results were calculated according to Cohen's d effect size [64].

$$
\mathrm{d}=\frac{M V_{\mathrm{t} 2}-M V_{\mathrm{t} 1}}{\mathrm{SD}_{\text {pool }}}
$$

This is interpreted in the following intervals: $0.2-0.5 \bumpeq$ small effect, $0.5-0.8 \bumpeq$ medium effect, $>0.8 \bumpeq$ large effect. ANOVA was used to verify the influence of the therapy form (standard therapy and additional robotic ball training) as well as the group affiliation (sequence of the therapy application) on differences in the assessments.

Furthermore, the root-mean-square error (RMSE) was calculated in order to include the minimum effect for the underlying sample in the interpretation based on the variability of the data after several measured attempts (grip strength, round block).

$$
\text { Effect }_{\min }=\mathrm{RMSE} \times 2.77
$$

The confidence interval for the effect was formed in order to further classify the results, thus allowing specification of a value range within which the true value for the effect for the population can be determined with $95 \%$ confidence.

$$
\text { Effect }_{\mathrm{Cl}}=\text { Mean Difference } \pm(1.96 \times \text { Standard error })
$$

\section{Results}

Twenty of 25 patients could complete the intervention in its entirety. There were dropouts in both Group $1(n=2)$ and Group $2(n=3)$. In four cases this was due to the severity of symptoms (particular- ly finger flexion spasticity), and in one case, too severe cognitive impairments. On the whole, grip strength increased by $4.5 \pm 3.6 \mathrm{~kg}$ $(p=0.000)$, corresponding to an improvement of $43.9 \pm 30.4$ to $53.8 \pm 33.8 \%$ relative to the healthy body half. Group 2 showed a lower initial level of grip strength compared to Group 1. Moderately affected patients $(n=11)$ improved by $5.4 \pm 2.8 \mathrm{~kg}(p=0.003)$, corresponding to an improvement of $16.0 \pm 9.1 \%$ relative to the unaffected upper extremity. Mildly affected $(n=4)$ patients improved by $7.3 \pm 2.9 \mathrm{~kg}(\bumpeq 5.5 \pm 5.9 \%)$, and the severely affected $(n=5)$ improved by $0.1 \pm 0.5 \mathrm{~kg}(\hat{=} 0.0 \pm 0.7 \%)$. In the round block test as a measure of unilateral dexterity, the subjects were able to improve by $7.5 \pm 6.3$ successful attempts per minute $(p=0.000)$, corresponding to an improvement of $29.6 \pm 20.9$ to $40.2 \pm 25.9 \%$ relative to the healthy body half. Regarding this parameter, Group 2 demonstrated a weaker initial level compared to Group 1. Moderately affected patients $(n=14)$ improved by $10.0 \pm 6.0$ attempts were again the strongest group $(p=0.000)$, corresponding to an improvement of $13.5 \pm 9.9 \%$ relative to the unaffected upper extremity. Severely affected patients $(n=6)$ improved by $1.9 \pm 1.6$ successful attempts per minute $(\bumpeq 3.5 \pm 3.8 \%)$. Subjective health perception improved among all subjects by $12.4 \pm 13.0$ points $(p=0.001)$, although the clinically relevant difference of 14 points [63] was narrowly missed. The group of moderately affected patients $(n=15)$ reached this threshold with $16.8 \pm 11.9$ points $(p=0.000)$. Severely affected patients $(n=2)$ improved by $3.4 \pm 4.8$ points; mildly affected patients $(n=3)$ improved by $0.0 \pm 2.3$ points. Group 2 demonstrated fewer changes than Group 1 (Tab. 2).

Depending on the group at the respective study phase, the data clearly indicate that the greatest changes were achieved by both groups during the supplementary robotic ball training phase ( $\vee$ Fig. 5). In addition, the data trend of Group 1 shows that the training effects during standard therapy did not persist, and in fact, even declined slightly $(p=0.005, d=0.24)$. Twelve weeks after the intervention, grip strength, unilateral dexterity as well as subjective perception of health were still greater than the initial level. The form of therapy had a highly-significant influence on the differentials in grip strength (ANOVA, $p=0.000$ ) and unilateral dexterity (ANOVA, $p=0.000$ ) Group affiliation (sequence of therapeutic applications) had no significant influence on the differences in grip strength (ANOVA, $\mathrm{p}=0.346$ ) or unilateral dexterity (ANOVA, $p=0.269$ ). Regarding grip strength and health perception, both groups were at the same level, although initially Group 1 performed better in the round block test ( $\triangleright$ Fig. 5). The subjective health perception (QuickDASH) of both groups significantly improved during the robotic ball training phase $(p=0.001, d=-0.60)$ although the mean difference of $12.4 \pm 13.0$ varied substantially. If only moderately affected patients are analyzed, the mean difference increases to $16.8 \pm 11.9$ points ( $p=0.000, d=1.01$ ) which is clinically relevant [63]. Analysis of grip strength $(p=0.000, d=0.33)$ and unilateral dexterity $(p=0.000, d=0.47)$ after robotic ball training showed minor effects for the entire random sample. Both parameters showed greater improvement for moderately affected patients. Grip strength improved up to $66.6 \pm 15.2 \%(p=0.003, d=0.76)$, and unilateral dexterity increased to $53.4 \pm 18,0 \%(p=0.000$, $d=0.78$ ) of the capacity of the unaffected body half. The differential between grip strength and unilateral dexterity showed no statistically significant relationship $(p=0.099, r=0.38)$. In contrast to 


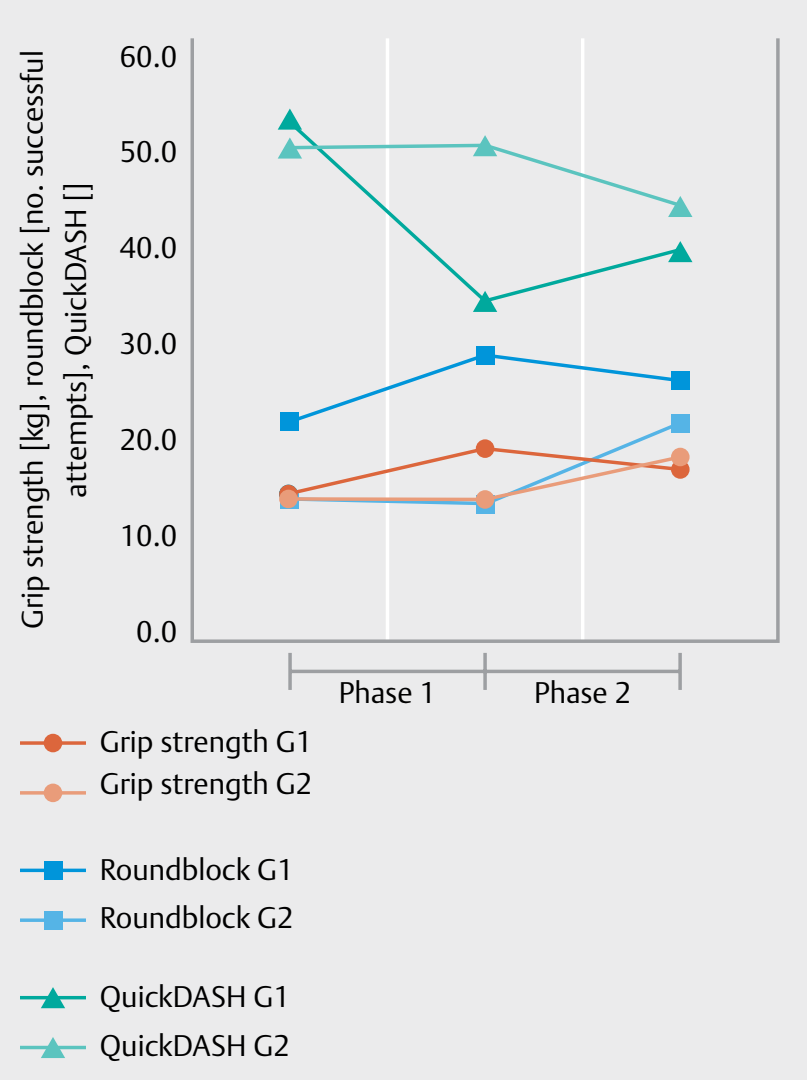

- Fig. 5 Mean value curves for grip strength, round block and QuickDASH related to the respective group Phase 1: Group 1 standard therapy + robotic ball therapy, Group 2: standard therapy Phase 2 Group 1: standard therapy - Group 2: standard therapy + robotic ball therapy. the difference in unilateral dexterity $(p=0.5, r=-0.16)$, median grip strength was significantly related to the difference in subjective health perception $(p=0.042, r=-0.459)$.

Individual case analysis illustrates the heterogeneity of the sample performance level. In particular, the group of severely affected patients demonstrated fewer changes in the assessments in the course of the study ( $\triangleright$ Fig. $\mathbf{6})$. At the start of the intervention, strong correlations $\left(p=0.000, R^{2}=0.768, d=1.82\right.$ ) between health perception and grip strength or unilateral dexterity could be measured for the entire sample. In addition, an initially high level of performance seemed to be improvable in some cases ( $>$ Fig. 6). On average, Group 1 showed higher performance in terms of grip strength, and after completion of training, demonstrated greater effects ( $p=0.007, d=0.52)$ compared to Group $2(p=0.018$, $d=0.25)$. With approximately equal effects in the round block test (Group 1: $p=0.002, d=0.45$ and Group 2: $p=0.008, d=0.49$ ), the differing grip strength was decisive for the large distinction between the two groups in terms of subjective health perception ( $\triangleright$ Fig. 5). Group 1 showed a clinically-relevant change of 14 $(p=0.002, d=-1.16)$, whereas in Group 2 only a small effect $(p=0.289, d=-0.38)$ was achieved ( $\mathbf{F i g} .5)$. The correlation between the difference in the perception of health and the differences between gripping strength and unilateral dexterity was not statistically significant ( $p=0.133, R^{2}=0.118, d=0.37$ ).

For the most part the data show a similar progression with few to no changes occurring in the standard therapy phase and distinct changes occurring with supplemental robotic ball therapy. Comparison of the standard therapy phases shows that the higher level of grip strength in Group 1 did not persist as a consequence of robotic ball training $(-2.16 \mathrm{~kg})$, whereas in Group 2 the differences in grip strength during the standard therapy phase were minimal $(-0.4 \mathrm{~kg})(\triangleright$ Fig. 7). The median differentials in this phase differed
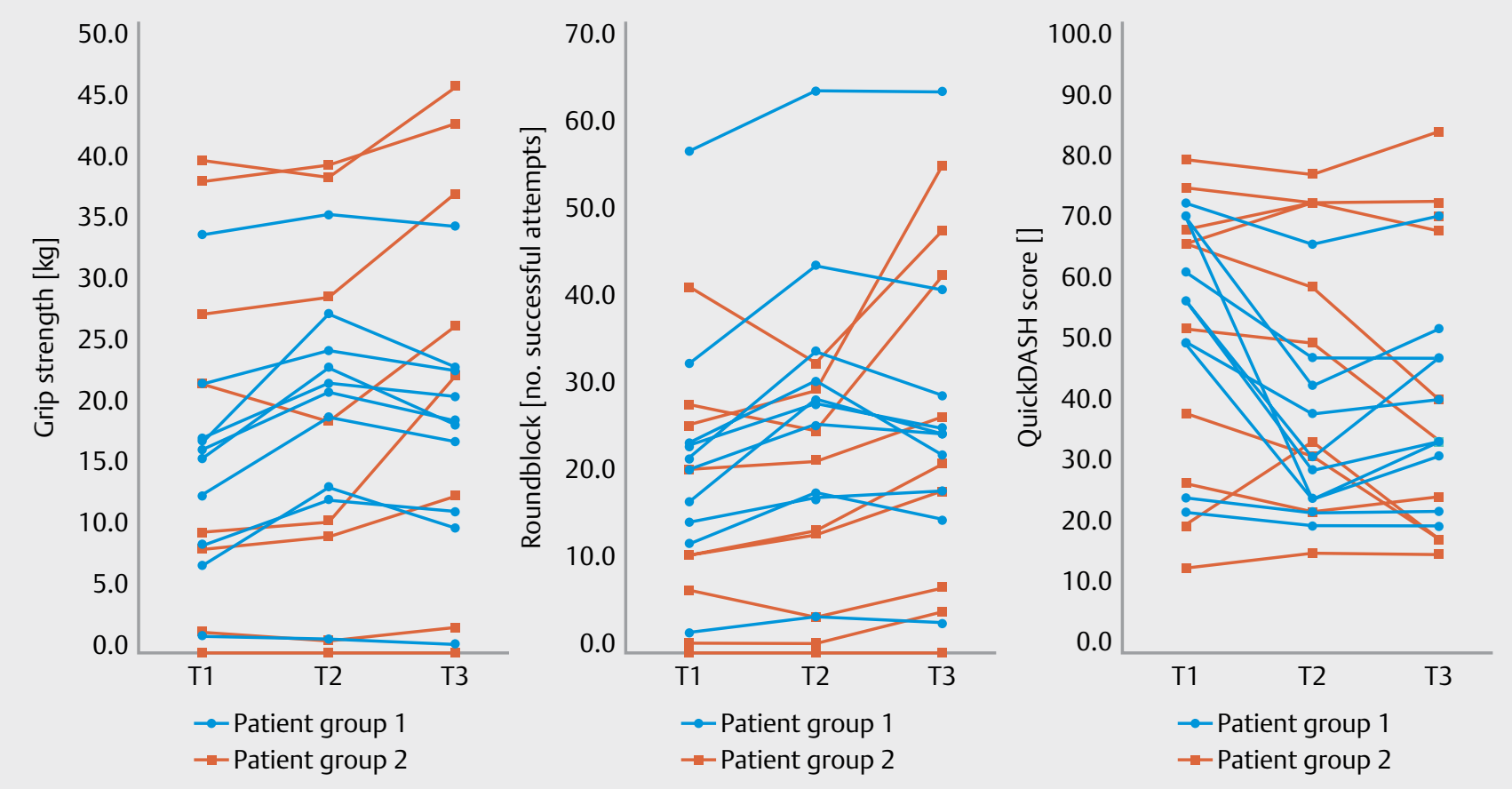

- Fig. 6 Changes in grip strength, round block and QuickDASH of each subject. 


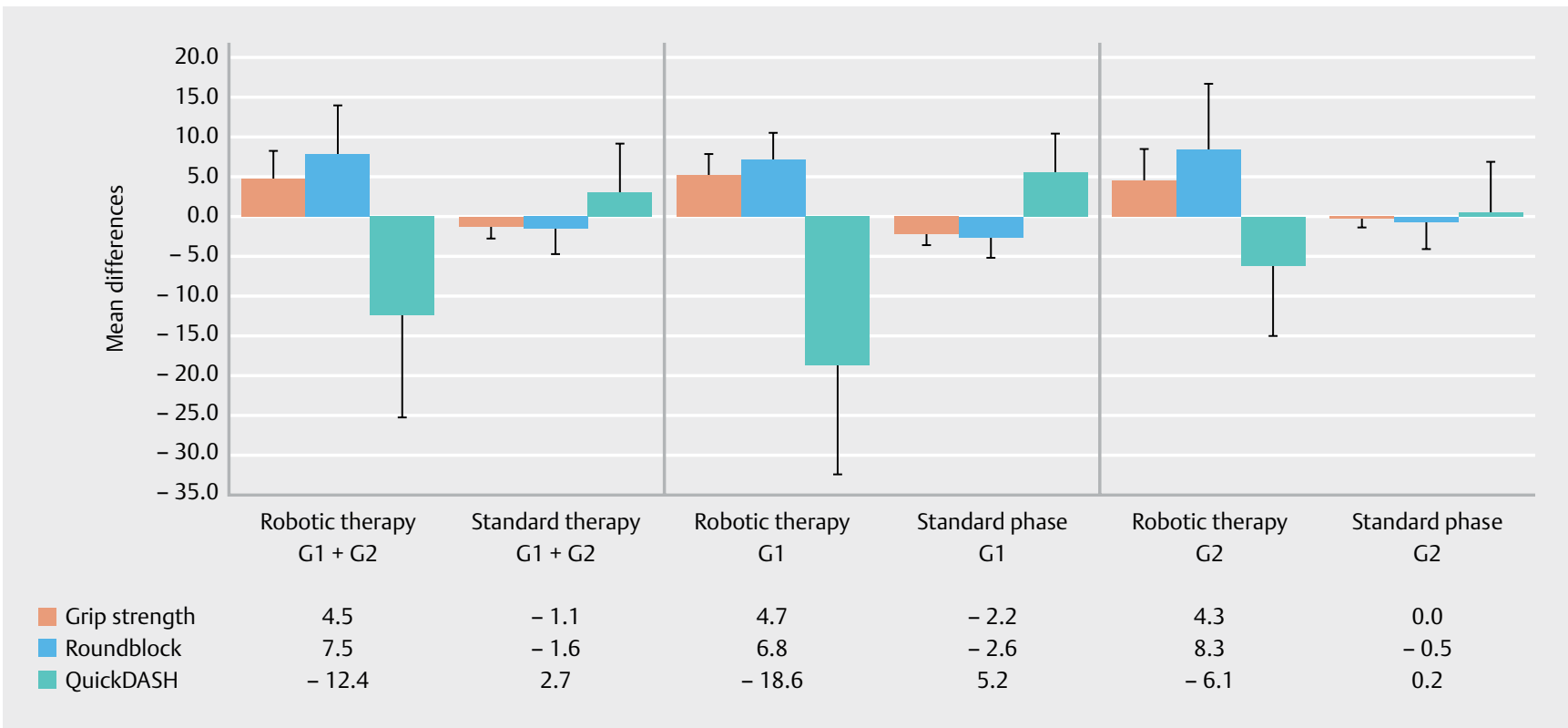

- Fig. 7 Mean differences for grip strength [kg], round block [number of successful attempts] and QuickDash [score] in the respective study phases for the entire sample $(G 1+G 2)$ as well as differentiated for Group 1 (G1) and Group 2 (G2).

- Table 1 Anthropometry of the sample and stroke characteristics.

\begin{tabular}{|c|c|c|c|c|c|c|c|c|}
\hline Gender & Age [years] & Size [cm] & Weight [kg] & $\begin{array}{c}\text { Insult } \\
\text { type }\end{array}$ & $\begin{array}{c}\text { Post-stroke } \\
\text { [months] }\end{array}$ & $\begin{array}{c}\text { Symptom } \\
\text { side }\end{array}$ & $\begin{array}{c}\text { Handed- } \\
\text { ness }\end{array}$ \\
\hline $\mathbf{1 5} \mathrm{m}, 10$ & $60.0 \pm 10.0$ & $172.5 \pm 13.8$ & $79.5 \pm 13.8$ & $201,5 \mathrm{H}$ & $89.8 \pm 72.6$ & $14 \mathrm{r}, 11 \mathrm{I}$ & $24 \mathrm{r}, 1 \mathrm{I}$ & $23.8 \pm 7.1$ \\
\hline
\end{tabular}

m male, $\mathbf{f}$ female, I ischemic, $\mathbf{H}$ hemorrhagic, $\mathbf{r}$ right, I left, MoCa Montreal Cognitive Assessment (Normal is $>26$ points)

significantly in this phase $(\mathrm{p}=0.004)$. Grip strength and unilateral dexterity increased; analogously the QuickDASH score declined, indicating improved subjective health perception.

\section{Discussion}

The data show that improved grip strength, combined with better everyday functioning, had a positive effect on the patients' subjective health perception. The strength of the hand when grasping is considered a prognostic indicator as well as a measure of the damage to the upper extremities in stroke patients [60]. This parameter is also a marker for estimating indication-specific mortality for middle-aged and older people and can be used as a predictor of morbidity, infirmity and functional impairment $[65,66]$. However, a relevant change in the subjective perception of health among either severely or mildly affected patients due to additional therapy was not achieved. Severely pronounced symptoms could not therefore be improved so significantly that the patients' general health perception was positively influenced. In mildly impaired patients, the potential for improving health was low even before initiation of robotic ball therapy. Noticeable group differentials in grip strength, unilateral dexterity and health perception are due to the randomized and thus varying group distribution of the sub- jects. The number of severely affected patients was greater in Group 2, which may explain the reduced effects. Differentiated analysis suggests that the therapy concept is not equally suitable for all stroke patients, but can complement the therapy, especially in moderately affected patients. In addition, non-specific effects should be taken into account which may have influenced the causes of the effects. On the one hand, patients may have been particularly motivated by the innovative and previously completely unknown therapy opportunity. Furthermore, the intensity and scope of the therapy were significantly increased. The new and unique training stimulus had a particularly favorable effect on the therapy results ( $\triangleright$ Table $\mathbf{2}$ ).

In addition to the results from the quantitative data analysis, direct patient feedback was important in order to document further changes. In addition to the therapy time, the patients' daily routine was taken into account. Behavior changes, for example in the form of additional use of the affected half of the body with more self-confidence due to increased ability, could additionally influence the effects. Individual discussions frequently revealed a patient's readiness to increasingly use the affected body half. Positive perceptions such as increased strength and dexterity as well as a somewhat improved exercise tolerance motivated the moderately affected in particular to apply different aspects of the training to everyday life, 


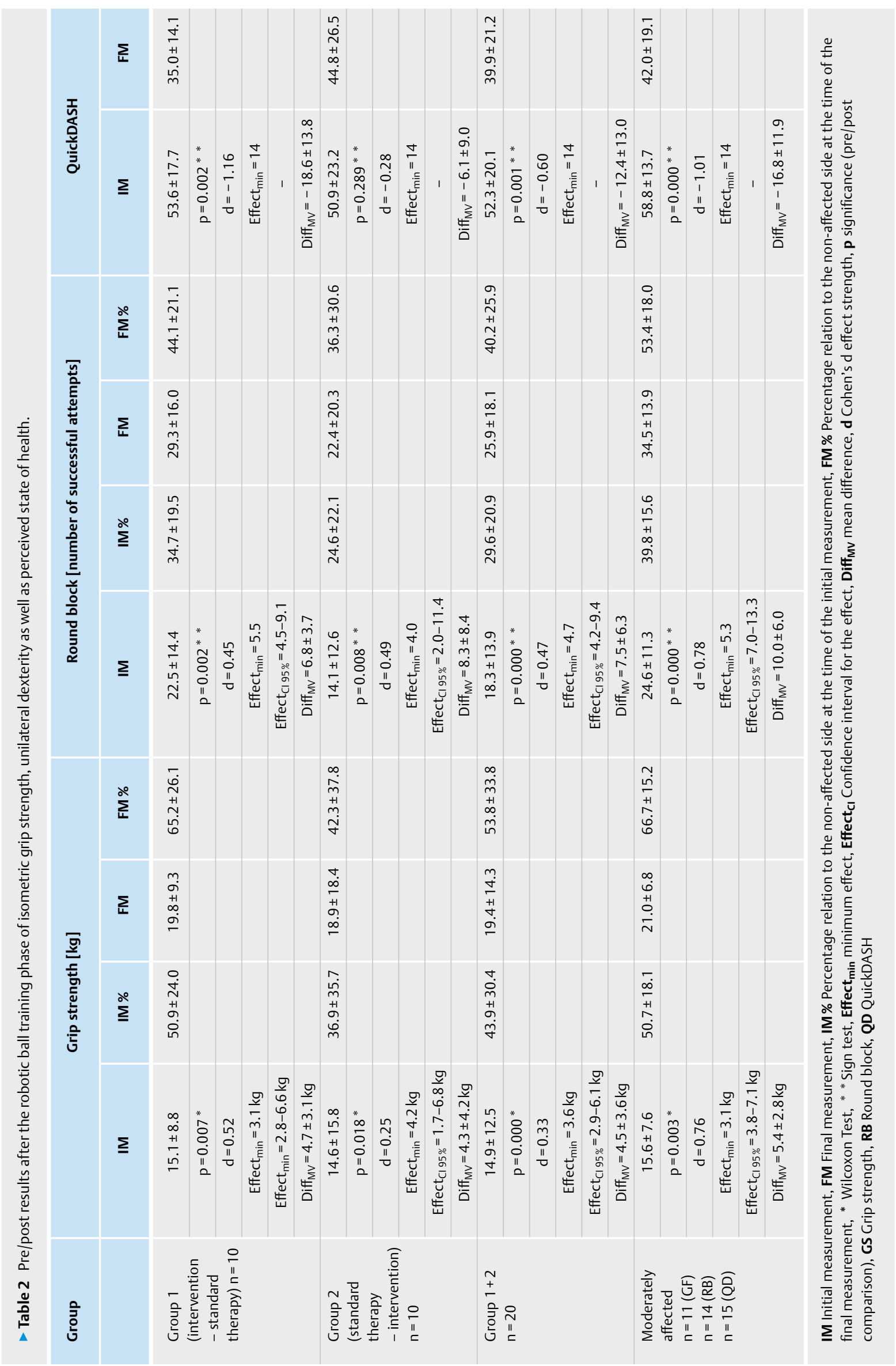


especially including gripping and using objects (e. g. hanging laundry, cooking, carrying utensils, using a keyboard). Thus, positive experiences in daily life and during training could contribute to increasing acceptance of the therapy concept and being open to new activities. Several patients demonstrated the willingness to try new movements with the injured side and to consciously integrate them more often into their everyday life.

Based on an objective data analysis in combination with subjective experience reports and observations during therapy with robotic ball training, it was possible to determine that the group of moderately-affected patients benefited the most from this measure (Tab. 2). Patients' symptoms allowed the implementation of various game activities with tolerable challenges and intensity. Very severely affected patients were generally able to perform the robotic ball therapy; however brain damage was so severe in these cases that this movement-therapeutic measure had its limits (4 dropouts due to great motor limitations). Although these patients could perform fewer play variations, nevertheless, they profited from the therapy, reporting a noticeable relaxation of muscle tone in the hand and arm immediately after the therapy session, which continued for up to three hours after therapy. The games were particularly welcomed by patients undergoing long-term therapy who saw them as a goal-oriented, motivating and entertaining addition to the therapy routine. However, the dropouts show the limits of feasibility. Severe spasticity in the lower arm or the fingers in particular can make it impossible to hold the robotic ball or smartphone and thus perform the movements.

Prior experience with the robotic ball shows the potentials of this therapeutic concept. High acceptance by patients and therapists due to entertaining and diversified therapy activities contributed to motivation and compliance. At the same time, these activities provided a measurable benefit with respect to the patients' motor-related parameters. It remains to be seen whether minimal setup effort and intuitive operation allow independent use by trained patients in the home environment. Furthermore, the results should be verified based on a larger patient sample. In addition, brain activation (e. g. via fMRI, fNIRS, TMS, EEG) could be investigated in order to determine the possible effect of the movements on neurophysiological processes (e. g. hemodynamics, electrical activity). It would then be possible to compare the extent and localization of brain activation with other activities and draw conclusions about processes of neurogenesis, plasticity and neuroprotection. The application of the therapy concept should be studied with respect to other pathologies, such as Parkinson's disease or multiple sclerosis.

\section{Summary and Outlook}

1. Additional therapy using a robotic ball could profitably supplement standard therapy. Positive changes in grip strength, unilateral dexterity and subjective sense of health were apparent in the supplemental robotic ball training phase; however, performance in the standard therapy phase largely stagnated. Improvement in grip strength was related to an improved perception of health. Non-specific effects in conjunction with the new, unfamiliar training stimulus may have additionally influenced the results.
2. Objective data analysis, subjective observations as well as patient reports demonstrated the benefit of the therapy concept for moderately affected patients. Particularly in the vase of very severe symptom manifestation, not all therapeutic activities could be completely performed; therefore only minor effects could be achieved. Especially severe motor or cognitive limitations could pose insurmountable barriers for patients; therefore the therapy concept could not be employed in individual cases.

To verify the results, robotic ball therapy should be used in a larger randomized study. Single-case analysis of the data show heterogeneity within the random sample and corresponding differences in effects. Application of this approach in the home environment should be studied. Furthermore, new specific therapeutic activities should be developed for stroke patients.

\section{Conflict of Interest}

The authors declare no conflict of interest.

\section{References}

[1] Busch M, Schienkiewitz A, Nowossadeck E, Gößwald A. Prävalenz des Schlaganfalls bei Erwachsenen im Alter von 40 bis 79 Jahren in Deutschland. Bundesgesundheitsblatt Gesundheitsforschung Gesundheitsschutz 2013; 5-6: 656-660

[2] Heuschmann P, Busse O, Wagner M et al. Schlaganfallhäufigkeit und Versorgung von Schlaganfallpatienten in Deutschland. Akt Neurol 2010; 37: 333-340

[3] Kolominsky-Rabas PL, Sarti C, Heuschmann PU et al. A prospective community-based study of stroke in Germany-the Erlangen Stroke Project (ESPRO) incidence and case fatality at 1,3 , and 12 months. Stroke1998 29: 2501-2506

[4] Palm F, Urbanek C, Rose S et al. Stroke Incidence and Survival in Ludwigshafen am Rhein, Germany. Stroke 2010; 41: 1865-1870

[5] Johnston SC, Mendis S, Mathers CD. Global variation in stroke burden and mortality: Estimates from monitoring, surveillance, and modelling. Lancet Neurol 2009; 8: 345-354

[6] Heuschmann P, Di Carlo A, Bejot Y et al. Incidence of stroke in Europe at the beginning of the 21st century. Stroke 2009; 40: 1557-1563

[7] Wolf SL, Winstein C], Miller JP et al. Effect of constraint-induced movement therapy on upper extremity function 3 to 9 months after stroke: the EXCITE randomized clinical trial. JAMA 2006; 296: 2095-2104

[8] Broeks J, Lankhorst G, Rumping K, Prevo A. The long-term outcome of arm function after stroke: results of a follow-up study. Disabil Rehabil 1999; 21: 357-364

[9] Langhorne P, Coupar F, Pollock A. Motor recovery after stroke: A systematic review. Lancet Neurol 2009; 8: 741-754

[10] Kwakkel G, Kollen B], Wagenaar RC. Therapy impact on functional recovery in stroke rehabilitation: a critical review of the literature. Physiotherapy 1999; 85: 377-391

[11] Goldie P, Matyas T, Kinsella G. Movement rehabilitation following stroke. La Trobe University Victoria: Department of Health Housing and Community Services; 1993

[12] Schubert F, Lalouschek W. Schlaganfall. In: Lehrner J, Pusswald G, Fertl E et al. (eds.) Klinische Neuropsychologie. Grundlagen - Diagnostik Rehabilitation. Heidelberg: Springer; 2006: 345-356 
[13] Hauptmann B. Von der Theorie zur Praxis: Grundlagen prozedualen und motorischen Lernens. In: Dettmers C, Bülau P, Weiller C, (eds.) Schlaganfall Rehabilitation. Bad Honnef: Hippocampus Verlag; 2007: 25-52

[14] Wulf G. Motorisches Lernen: Einflussgrößen und ihre Optimierung. In: Dettmers C, Bülau P, Weiller C, eds. Schlaganfall Rehabilitation. Bad Honnef: Hippocampus Verlag; 2008: 3-24

[15] McLean DE. Medical complications experienced by a cohort of stroke survivors during inpatient, tertiary-level stroke rehabilitation. Arch Phys Med Rehabil 2004; 85: 466-469

[16] Shelton F, Reding M. Effect of lesion location on upper limb motor recovery after stroke. Stroke 2001; 32: 107-112

[17] Azab M, Al-Jarrah M, Nazzal M et al. Effectiveness of constraintinduced movement therapy (CIMT) as home-based therapy on Barthel Index in patients with chronic stroke. Top Stroke Rehabil 2009; 16: 207-211

[18] Dromerick AW, Edwards DF, Hahn M et al. Does the application of constraint-induced movement therapy during acute rehabilitation reduce arm impairment after ischemic stroke? Stroke 2000; 31: 2984-2988

[19] Hakkennes S, Keating JL. Constraint-induced movement therapy following stroke: A systematic review of randomised controlled trials. Aust J Physiother 2005; 51: 221-231

[20] Kunkel A, Kopp B, Müller G et al. Constraint-induced movement therapy for motor recovery in chronic stroke patients. Arch Phys Med Rehabil 1999; 80: 624-628

[21] Miltner WH, Bauder $\mathrm{H}$, Sommer $\mathrm{M}$ et al Effects of constraint-induced movement therapy on patients with chronic motor deficits after stroke a replication. Stroke 1999; 30: 586-592

[22] Sirtori V, Corbetta D, Moja L, Gatti R. Constraint-induced movement therapy for upper extremities in stroke patients. The Cochrane Library 2009; 1-63

[23] Wolf SL, Thompson PA, Winstein C] et al. The EXCITE stroke trial comparing early and delayed constraint-induced movement therapy. Stroke 2010; 41: 2309-2315

[24] Wolf SL, Winstein C], Miller JP et al. The EXCITE trial: Retention of improved upper extremity function among stroke survivors receiving Cl movement therapy. Lancet Neurol 2008; 7: 33

[25] Allet L, Knols RH, Shirato K, de Bruin ED. Wearable systems for monitoring mobility-related activities in chronic disease: a systematic review. Sensors 2010; 10: 9026-9052

[26] Bonato P. Wearable sensors and systems. IEEE Eng Med Biol Mag 2010; 29: $25-36$

[27] Dobkin BH, Dorsch A. The promise of mHealth daily activity monitoring and outcome assessments by wearable sensors. Neurorehabil Neural Repair 2011; 25: 788-798

[28] Lohse KR, Hilderman CG, Cheung KL et al. Virtual reality therapy for adults post-stroke: A systematic review and meta-analysis exploring virtual environments and commercial games in therapy. PloS One 2014; 9: e93318

[29] Loureiro RC, Harwin WS, Nagai K et al. Advances in upper limb stroke rehabilitation: A technology push. Med Biol Eng Comput 2011; 49: 1103-1118

[30] Webster D, Celik O. Systematic review of Kinect applications in elderly care and stroke rehabilitation. J Neuroeng Rehabil 2014; 11: 108

[31] Alankus G, Lazar A, May M, Kelleher C. Towards customizable games for stroke rehabilitation. CHI 2010: Therapy and Rehabilitation 2010; 2113-2122

[32] Burke J, McNeill M, Charles D et al. Serious games for upper limb rehabilitation following stroke. Conference in Games and Virtual Worlds for Serious Applications. 2009; 103-110
[33] Burke ], McNeill M, Charles DK et al. Optimising engagement for stroke rehabilitation using serious games. Vis Comput 2009; 25: 1085-1099

[34] Ferreira C, Guimarães V, Santos A, Sousa I. Gamification of stroke rehabilitation exercises using a smartphone. Proceedings of the 8 th International Conference on Pervasive Computing Technologies for Healthcare. Oldenburg 2014; 282-285.

[35] Neuendorf T, Zschaebitz D, Nitzsche N, Schulz H. Neurorehabilitation mit einem Roboterball - ein geeignetes Therapiekonzept? Neurorehabilitation with a robotic ball - an applicable therapy concept? Neuroreha 2017; 9: 41-44

[36] Neuendorf T, Zschaebitz D, Nitzsche N, Schulz H. Technik-gestützte Bewegungstherapie der oberen Extremitäten nach Schlaganfall - eine aktuelle Übersicht. NeutroTransmitter 2017; 28: 42-47

[37] Neuendorf T, Zschaebitz D, Nitzsche N, Schulz H. Therapeutischer Effekt Sensor-gestützter Rehabilitationssysteme bei Schlaganfallpatienten. Therapeutic effect of sensor-based rehabilitation systems in stroke patients. Akt Neurol 2016; 43: 24-31

[38] Colomer C, Llorens R, Noé E, Alcañiz M. Effect of a mixed reality-based intervention on arm, hand, and finger function on chronic stroke. J Neuroeng Rehabil 2016; 13: 1-10

[39] Khotimah WN, Sholikah RW, Hariadi RR. Sitting to standing and walking therapy for post-stroke patients using virtual reality system. International Conference on Information, Communication Technology and System (ICTS). IEEE 2015, 145-150

[40] Lange B, Chang C-Y, Suma E et al. Development and evaluation of low cost game-based balance rehabilitation tool using the Microsoft Kinect sensor. Conf Proc IEEE Eng Med Biol Soc 2011; 1831-1834

[41] Llorens R, Alcaniz M, Colomer C, Navarro MD. Balance recovery through virtual stepping exercises using Kinect skeleton tracking: A follow-up study with chronic stroke patients. Stud Health Technol Inform 2012; 181: 108-112

[42] Martel MRF, Colussi EL, Marchi ACBD. Effects of a video game-based intervention on the attention and functional independence of older adults after cerebrovascular accident. Fisioterapia e Pesquisa 2016; 23 : 52-58

[43] Mousavi Hondori H, Khademi M. A review on technical and clinical impact of microsoft kinect on physical therapy and rehabilitation. J Med Eng 2014; 2014: 866514; doi:10.1155/2014/846514

[44] Sin H, Lee G. Additional virtual reality training using Xbox Kinect in stroke survivors with hemiplegia. Am J Phys Med Rehabil 2013; 92: 871-880

[45] Goble DJ, Cone BL, Fling BW. Using the Wii Fit as a tool for balance assessment and neurorehabilitation: The first half decade of “Wii-search"? J Neuroeng Rehabil 2014; 11: 3-11

[46] Joo LY, Yin TS, Xu D et al. A feasibility study using interactive commercial off-the-shelf computer gaming in upper limb rehabilitation in patients after stroke. J Rehabil Med 2010; 42: 437-441

[47] Saposnik G, Teasell R, Mamdani M et al. Effectiveness of virtual reality using Wii gaming technology in stroke rehabilitation a pilot randomized clinical trial and proof of principle. Stroke 2010; 41: 14771484

[48] Flynn S, Palma P, Bender A. Feasibility of using the Sony PlayStation 2 gaming platform for an individual poststroke: A case report. J Neurol Phys Ther 2007; 31: 180-189

[49] Carabeo CGG, Dalida CMM, Padilla EMZ et al. Stroke patient rehabilitation a pilot study of an android-based game. Simulation \& Gaming 2014; 45: 151-166

[50] English BA, Howard AM. An adaptive robotic tablet gaming system for post-stroke hand function rehabilitation. In: Proceedings of the Tenth Annual ACM/IEEE International Conference on Human-Robot Interaction Extended Abstracts. 2015; 207-208 
[51] Rand D, Schejter-Margalit T, Dudkiewicz I et al. The use of the iPad for poststroke hand rehabilitation; a pilot study. International Conference on Virtual Rehabilitation (ICVR). IEEE 2013; 109-113

[52] Rand D, Zeilig G, Kizony R. Rehab-let: touchscreen tablet for self-training impaired dexterity post stroke: study protocol for a pilot randomized controlled trial. Trials 2015; 16: 277

[53] Ma M, Bechkoum K. Serious games for movement therapy after stroke. In: Systems, Man and Cybernetics. IEEE International Conference on Systems, Man and Cybernetics 2008: 1872-1877

[54] Saposnik G, Cohen LG, Mamdani M et al. Efficacy and safety of non-immersive virtual reality exercising in stroke rehabilitation (EVREST): A randomised, multicentre, single-blind, controlled trial. Lancet Neurol 2016; 15: 1019-1027

[55] Shin J-H, Ryu H, Jang SH. A task-specific interactive game-based virtual reality rehabilitation system for patients with stroke: A usability test and two clinical experiments. J Neuroeng Rehabil 2014; 11: 32

[56] Turolla A, Dam M, Ventura L et al. Virtual reality for the rehabilitation of the upper limb motor function after stroke: A prospective controlled trial. J Neuroeng Rehabil 213 10: 85

[57] Veerbeek JM, van Wegen E, van Peppen $R$ et al What is the evidence for physical therapy poststroke? A systematic review and meta-analysis. PloS One 2014; 9: e87987

[58] Nasreddine ZS, Phillips NA, Bédirian V et al. The Montreal Cognitive Assessment, MoCA: A brief screening tool for mild cognitive impairment. J Am Geriatr Soc 2005; 53: 695-699
[59] Boissy P, Bourbonnais D, Carlotti MM et al Maximal grip force in chronic stroke subjects and its relationship to global upper extremity function. Clin Rehabil 1999; 13: 354-362

[60] Sunderland A, Tinson D, Bradley L, Hewer RL. Arm function after stroke. An evaluation of grip strength as a measure of recovery and a prognostic indicator. J Neurol Neurosurg Psychiatry 1989; 52: 1267-1272

[61] Beaton DE, Wright JG, Katz JN et al. Development of the QuickDASH: comparison of three item-reduction approaches. J Bone Joint Surg Am 2005; 87: 1038-1046

[62] Gummesson C, Ward MM, Atroshi I. The shortened disabilities of the arm, shoulder and hand questionnaire (QuickDASH): Validity and reliability based on responses within the full-length DASH. BMC Musculoskelet Disord 2006; 7: 44

[63] Sorensen AA, Howard D, Tan WH et al. Minimal clinically important differences of 3 patient-rated outcomes instruments. J Hand Surg Am 2013; 38: 641-649

[64] Cohen J. Statistical Power Analysis for the Behavioural Sciences. 2nd ed. Ortn: Lawrence Erlbaum Associates; 1988

[65] Sasaki H, Kasagi F, Yamada M, Fujita S. Grip strength predicts cause-specific mortality in middle-aged and elderly persons. Am J Med 2007; 120: 337-342

[66] Syddall H, Cooper C, Martin F et al. Is grip strength a useful single marker of frailty? Age Ageing 2003; 32: 650-656 